\title{
Influence of Processing Type in the Morphology of Membranes Obtained from PA6/MMT Nanocomposites
}

\author{
Rodholfo da Silva Barbosa Ferreira, Caio Henrique do Ó Pereira, Rene Anisio da Paz, \\ Amanda Melissa Damião Leite, Edcleide Maria Araújo, and Hélio de Lucena Lira
}

Federal University of Campina Grande, Avenida Aprígio Veloso, 882 Bodocongó, 58429-140 Campina Grande, PB, Brazil

Correspondence should be addressed to Rodholfo da Silva Barbosa Ferreira; rodholfoferreira@gmail.com

Received 30 November 2013; Revised 25 February 2014; Accepted 25 February 2014; Published 16 April 2014

Academic Editor: A. G. Barbosa de Lima

Copyright ( $) 2014$ Rodholfo da Silva Barbosa Ferreira et al. This is an open access article distributed under the Creative Commons Attribution License, which permits unrestricted use, distribution, and reproduction in any medium, provided the original work is properly cited.

\begin{abstract}
The nanocomposites have an extensive use in the current process of membrane preparation, taking into account their unique features as membranes. Thus, the study of nanocomposite processing to obtain membranes is highly important. In this work, Brazilian clay was used (Brasgel PA) for the preparation of polyamide/clay nanocomposite. The nanocomposites were produced in a high rotation homogenizer and in a twin screw extruder. From the nanocomposites and pure polymers processed in the two equipments, membranes were prepared by the immersion-precipitation method, using formic acid as solvent. By X-ray diffraction (XRD), the formation of exfoliated and/or partially exfoliated structures with changes in the crystalline phases of the polyamide was observed. From scanning electron microscopy images, it was observed that the processing clearly influenced the membrane morphology.
\end{abstract}

\section{Introduction}

Recently, the membrane technology is applied in several industrial processes presenting numerous advantages, such as continuous processing with low energy consumption and easy combination with other separation processes [1]. In the early 1970s, besides the development of classical separation techniques, new synthetic membranes, which can be used as a selective barrier, were developed. The synthetic membranes were designed to improve the characteristics of selectivity and permeability of natural membranes. The addition of inorganic nanoparticles (clay) greatly improves the filtration properties of the membrane. Several studies indicate that the addition of inorganic nanoparticles in the polymer solution, used to prepare membrane by phase inversion, can control the formation and growth of macropores, increase the number of small pores, and improve the hydrophilicity, porosity, and permeability and mechanical and antifouling properties $[2,3]$.

The membranes can be considered polymeric or inorganic films that work as a semipermeable barrier to filtration in a molecular scale, separating two phases and restricting, totally or partially, the transport of one or several chemical species (solutes) present in a solution $[4,5]$.

Most membranes used worldwide and so-called second generation are produced from synthetic polymers, such as polyamide, polysulfone, polyacrylonitrile, polycarbonate, and poly(vinylidene fluoride), among others. They show resistance to the action of strong acids and bases $(\mathrm{pH}$ from 2 to 12) and support temperatures close to or even superior to $100^{\circ} \mathrm{C}$. These membranes can also be used with nonaqueous solvents and have long lifetime [6].

Most of polymer membranes used commercially are prepared by phase inversion technique, which consists of three main steps: preparation of polymer solution, spreading the solution on a surface forming a film with controlled thickness, and, finally, precipitating nonsolvent for formation of the polymeric structure of the membranes by using a phase separation system $[7,8]$.

Many materials may be used to prepare polymer membranes, among them is the polyamide. This polymer presents high performance and excellent mechanical and thermal properties [9]. In addition, the polyamides being used as nanocomposites matrices where have presented attractive 
properties, for instance, barrier properties to gas permeation. The hybrids organic/inorganic films obtained from clay present a waterproofing due to the lamellas of montmorillonite that act as a barrier with less loads than the conventional composite films [10].

The polymer nanocomposites are hybrid materials where particles with nanometric size are dispersed in a polymeric matrix. They can be considered a new class of polymer composed of inorganic phases with ultrafine dimensions that interact with the polymer, thus offering a better combination of properties such as toughness and resistance, difficult to be achieved with pure polymer. Reinforced polymers with low content of clay (1 to $5 \%$ in mass) have raised interest in academic and industrial environments, due to the considerable improvement in the physical and mechanical properties, as well as permitting the processing from conventional techniques such as extrusion and/or injection [1113].

The aim of this work is to analyze the structure and morphology of polymeric membranes using X-ray diffraction (XRD) and scanning electron microscopy (SEM), respectively. The membranes were prepared by the phase inversion method from PA6/MMT nanocomposites.

\section{Materials and Methods}

2.1. Materials. A sample of Brasgel PA clay was used, supplied by Bentonit União do Nordeste (BUN), from Campina Grande, Paraiba, Brazil), with cation exchange capacity (CEC) of $90 \mathrm{meq} / 100 \mathrm{~g}$, and passed in a sieve ABNT 200 mesh. Polyamide 6 from Polyform B300, with average viscosity IV $=140-160 \mathrm{~mL} / \mathrm{g}$, in the form of granules in white was used. Formic acid PA from Vetec, with $98 \%$ of purity, was used as solvent to dissolve the polymer and nanocomposites to prepare the membranes.

\subsection{Methods}

2.2.1. Preparation of Nanocomposites. For the nanocomposites preparation, $1 \%$ was used in mass of clay to the polymer and two processing equipment: a high rotation homogenizer, $\mathrm{MH}-50 \mathrm{H}$ model, and a corotational twin screw extruder from Coperion. In the first, the clay was dispersed directly in the equipment. In the second, a concentrated (50:50\% in mass) in the homogenizer was obtained and then incorporated in a polymer matrix in the proportion of $1 \%$ in mass of clay, using the extruder. Processing conditions were as follows: mixed in the homogenizer for 30 to 40 seconds until PA6 melting. The processing in the extruder is done in a temperature of $260^{\circ} \mathrm{C}$ for 7 existing zones and a screw rotation of $250 \mathrm{rpm}$. For each processing step, all materials with polyamide 6 were dried in a circulating air oven at $80^{\circ} \mathrm{C}$ for $2 \mathrm{~h}$ and in a vacuum oven at $80^{\circ} \mathrm{C}$ for 24 hours.

2.2.2. Preparation of Membranes. For the membrane preparation, the phase inversion method was used through the immersion-precipitation technique. The polyamide and its

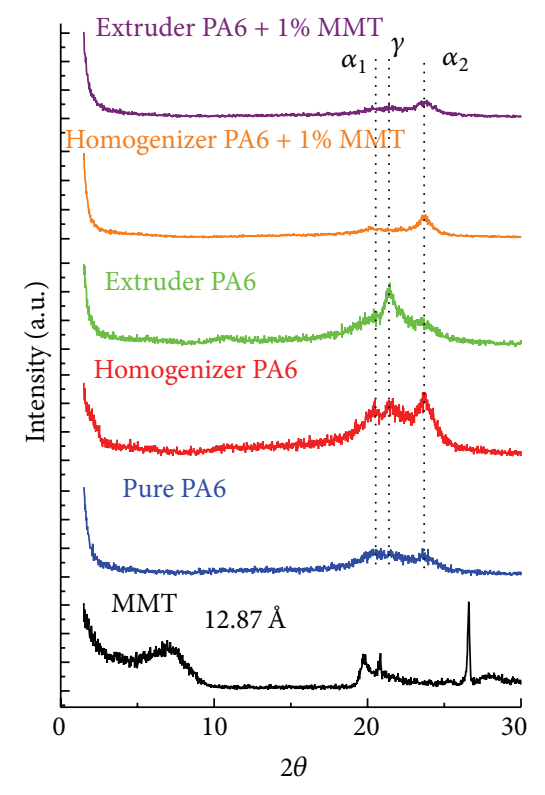

FIgURE 1: X-ray diffraction curves of clay, pure polyamide, and nanocomposites.

nanocomposites were dissolved in formic acid in a proportion of $20 \%$ in mass of polymer under constant stirring for 24 hours, for total polymer dissolution. The solution was spread in a glass plate, previously washed and dried. The spreading was done manually with a spacer and the polymer film was quickly immersed in a precipitation bath with distilled water. Then, the membranes were removed, washed with distilled water to remove the residual solvent, and dried at room temperature. This procedure is according to Leite [14]. The nomenclature used is the following: Pure PA6 (polyamide without processing), Extruder PA6, Homogenizer PA6, PA6 + $1 \% \mathrm{MMT}$, Extruder PA6 + 1\%MMT, and Homogenizer PA6 + $1 \% \mathrm{MMT}$

2.2.3. Materials Characterization. The nanocomposites were characterized by X-ray diffraction (XRD), using a Shimadzu XRD-6000 equipment, with $\mathrm{CuK} \alpha$ radiation $(\lambda=1.5418 \AA$ ), $40 \mathrm{kV}, 30 \mathrm{~mA}$, and scanning $2 \theta$ from $1.5^{\circ}$ to $30^{\circ}$ at a scanning rate of $2^{\circ} / \mathrm{min}$.

The membranes were characterized by scanning electron microscopy, using a SSX 550 Superscan from Shimadzu, operating at $15 \mathrm{kV}$. Both top and cross section surfaces of the membranes were evaluated. For the cross section analysis, the samples were fractured in liquid nitrogen to avoid plastic deformation. The surfaces were coated with gold.

\section{Results and Discussion}

3.1. X-Ray Diffraction (XRD). The analysis of X-ray diffraction of the bentonite clay (MMT) without treatment (Figure 1) revealed the presence of characteristic peaks of bentonite and other minerals such as quartz $(\mathrm{Q})$. A peak was observed in the interplanar distance of $12.77 \AA$, characteristic 


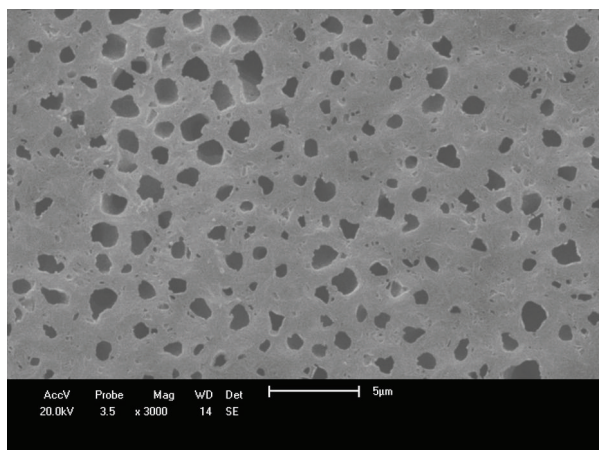

(a)

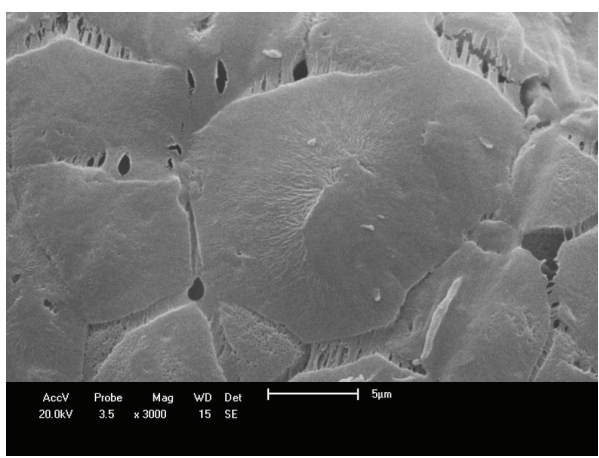

(c)

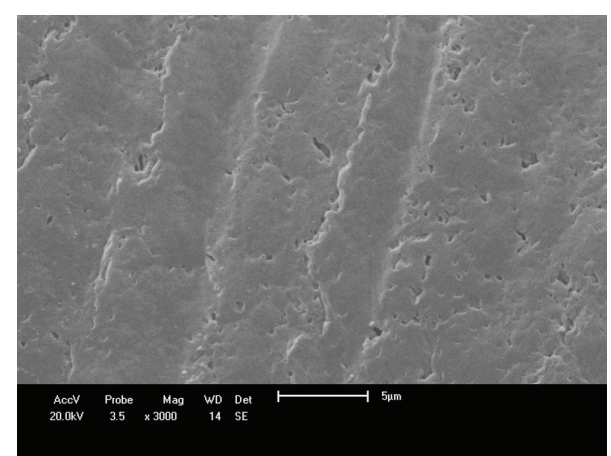

(b)

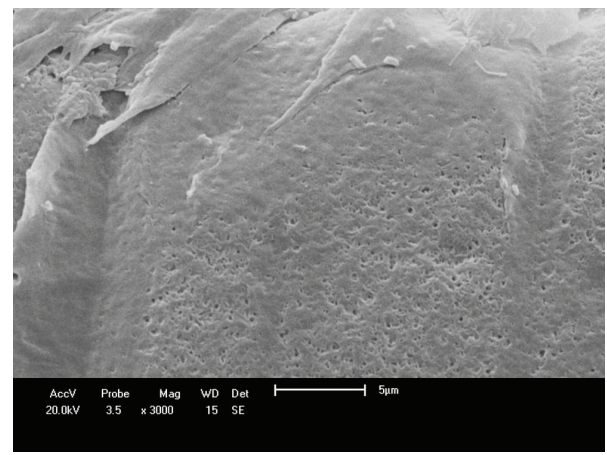

(d)

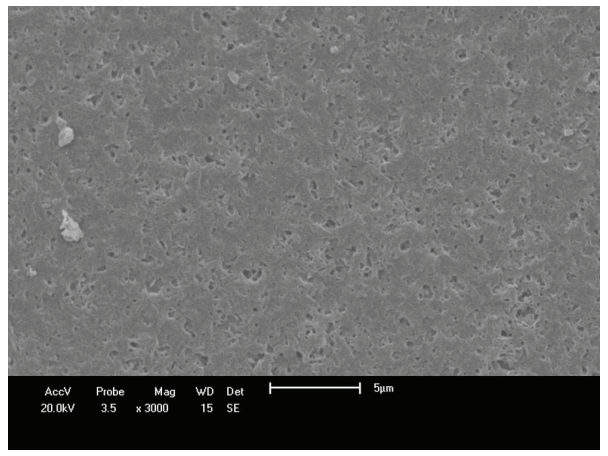

(e)

Figure 2: SEM images of the top surface of the membranes: (a) Pure PA6, (b) Homogenizer PA6, Extruder PA6, (c) Extruder PA6, (d) Homogenizer PA6 + 1\%MMT, and (e) Extruder PA6 + 1\%MMT.

of sodium montmorillonite with small hydration [15] (Santos, 1989).

Through the X-ray results, the presence of two peaks in the range from $20^{\circ}$ to $23^{\circ}$ can be observed, related to the crystalline planes (200) and (002) of the $\alpha$ phase of polyamide 6 . These results are in agreement with the literature $[14,16-18]$. A crystalline plane (001) that corresponds to the $\gamma$ phase of the polymer was also identified. This reflection occurred for all samples, with higher incidence for extruded polyamide 6 (close to $21^{\circ}$ ). In this case, it is possible to observe that the predominant crystalline phase of polyamide is $\alpha$. The polyamide 6 is a semicrystalline polymer and the enlargement of the peaks indicates the existence of amorphous regions. As can be seen, the incorporation of clay can change the shape of these peaks, modifying probably the crystallinity for PA6. According to Khanna and Kuhn [19], the polyamide 6 can assume two crystallographic forms ( $\alpha$ monoclinic and $\gamma$ monoclinic and/or pseudohexagonal).

From Figure 1, the disappearance of the characteristic peak of the clay can be seen, indicating a possible exfoliation and/or partial exfoliation of nanocomposites formed by polyamide $6+1 \%$ of clay. Similar behavior was observed by Ray and Okamoto and Fornes et al., for the polyamide 6/clay systems $[20,21]$.

However, for the sample PA6 extruded, a small contribution of the $\alpha$ crystalline phase and, more pronounced, the formation of $\gamma$ phase, which does not occur for the sample processed in the high rotation homogenizer, should be noted. This behavior indicates that the processing has influenced the formation of crystalline arrangement. 


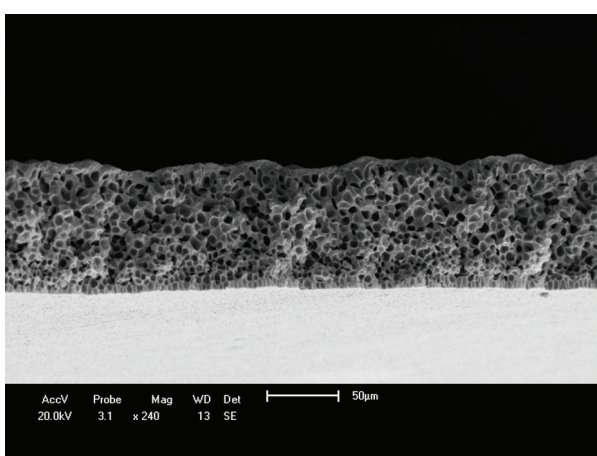

(a)

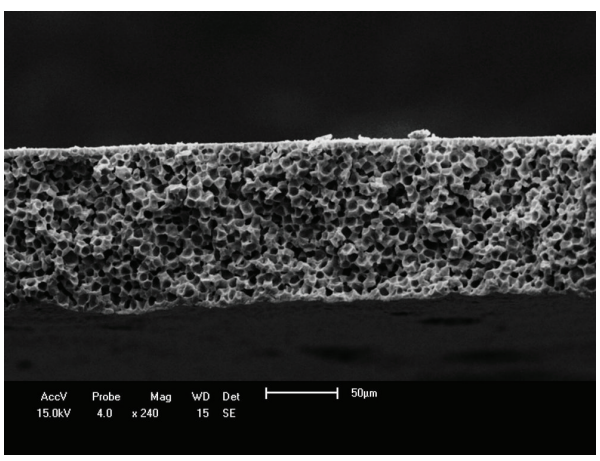

(c)

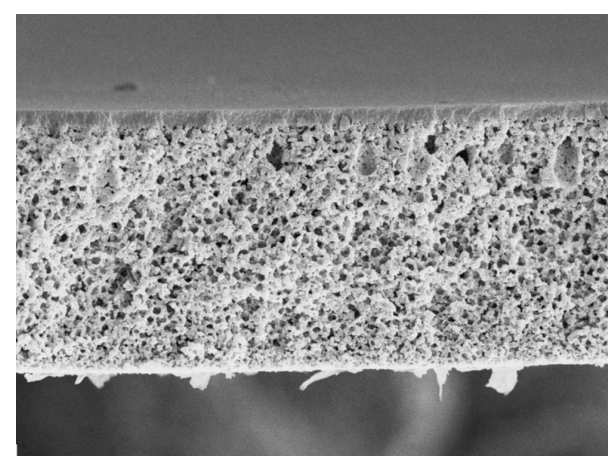

(b)

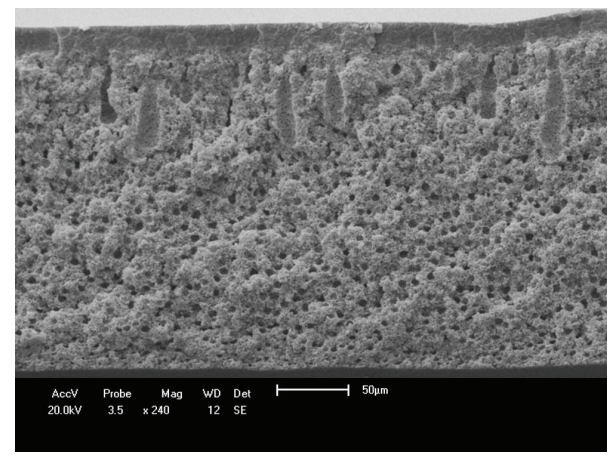

(d)

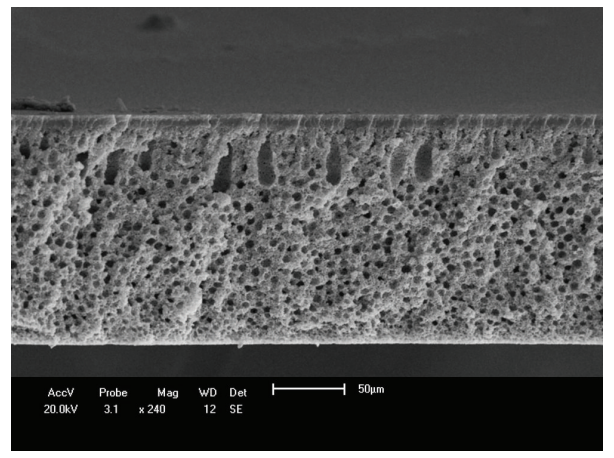

(e)

FIgURE 3: SEM images of the cross section of the membranes: (a) Pure PA6, (b) Homogenizer PA6, (c) Extruder PA6, (d) Homogenizer PA6+1\%MMT, and (e) Extruder PA6+1\%MMT.

\subsection{Scanning Electron Microscopy (SEM)}

3.2.1. Top Surface. Figure 2 presents the SEM images of the following membrane surfaces: Pure PA6, Homogenizer PA6, Extruder PA6, and their nanocomposites with $1 \%$ of clay.

From Figure 2(a), it can be verified that Pure PA6 presents pores with uniform distribution. It is possible to see that there are less pores for both Homogenizer PA6 (Figure 2(b)) and Extruder PA6 (Figure 2(c)), when compared to the morphology presented by Pure PA6. Possibly, this change could be due processing of material.

It was observed that the presence of clay (1\%) for the nanocomposites prepared in the homogenizer and in the extruder changed considerably the quantity and uniformity of pores in the membrane, compared to the pure PA6 membrane. The membranes prepared with nanocomposites with $1 \%$ of clay presented a greater number of pores due to the presence of clay in the polymer matrix.

3.2.2. Cross Section. Figure 3 presents the SEM images with an overview of the cross sections for the membranes: Pure PA6, Homogenizer PA6, Extruder PA6, and their nanocomposites with $1 \%$ of clay.

According to the SEM images, it can observed that PA6 (Figure 3(a)) presented a well-defined surface with micropores, allowing for a greater selectivity. The cross section indicates a thickness of approximately $92.5 \mu \mathrm{m}$, with uniform distribution of pores in the whole membrane. The Homogenizer PA6 membrane (Figure 3(b)) showed a wide selective layer, when compared with Pure PA6 membrane, with a thickness of approximately $183 \mu \mathrm{m}$ and good pore size 
distribution with presence of "fingers." The Extruder PA6 membrane (Figure 3(c)) presents a very thin selective layer when compared with pure PA6 and Homogenizer PA6, with a thickness of approximately $109 \mu \mathrm{m}$, with small, uniform, and interconnected pores. This behavior can be explained by the processing performed in the homogenizer and extruder. Membranes with $1 \%$ of clay show "finger" shaped pores with no connections, which block fluid flows through the membrane. The Homogenizer PA $6+1 \%$ MMT presented a thickness of approximately $242 \mu \mathrm{m}$. For the Extruder PA6 + $1 \%$ MMT, a thickness of approximately $161 \mu \mathrm{m}$ was observed.

\section{Conclusions}

Membranes were prepared from PA6/MMT nanocomposites. From X-ray diffraction results, it was observed that the nanocomposites presented exfoliated and/or partially exfoliated structure. From SEM images, it was observed that the Pure PA6 membrane presented uniform pores. Membrane PA6, prepared with nanocomposites processed in the homogenizer and extruder, presented small amount of pores, showing that the processing has influence in the morphology of the membranes. Membranes prepared from nanocomposites with $1 \%$ of clay presented more pores than PA6 membrane, showing that the presence of clay has considerably influenced the morphology. From the images showing the cross section of the membranes, it was observed that the processing influenced the thickness of the selective layer of the membranes. Membranes with clay had not interconnected pores and a thicker selective layer, which probably blocked flow membrane.

\section{Conflict of Interests}

The authors declare that there is no conflict of interests regarding the publication of this paper.

\section{Acknowledgments}

The authors are grateful to Bentonit União Nordeste (BUN), DEMa/UFCG, MCT/CNPq, CAPES, Petrobras, and PRH25/ANP for financial support.

\section{References}

[1] P. Poletto, J. Durate, M. S. Lunkes et al., "Avaliação das características de transporte em membranas de poliamida 66 preparadas com diferentes solventes," Polímeros, vol. 22, no. 3, pp. 273277, 2012.

[2] A. C. Habert, C. P. Borges, and R. Nobrega, Processo de Separação com Membranas, E-papers Serviços Editoriais Ltda, Rio de Janeiro, Brazil, 1 edition, 2006.

[3] Y. N. Yang, W. Jun, Z. Qing-zhu, C. Xue-si, and Z. Hui-xuan, "The research of rheology and thermodynamics of organicinorganic hybrid membrane during the membrane formation," Journal of Membrane Science, vol. 311, no. 1-2, pp. 200-207, 2008.

[4] A. Hamza, V. A. Pham, T. Matsuura, and J. P. Santerre, "Development of membranes with low surface energy to reduce the fouling in ultrafiltration applications," Journal of Membrane Science, vol. 131, no. 1-2, pp. 217-227, 1997.

[5] J. Han, W. Lee, J. M. Choi, R. Patel, and B.-R. Min, "Characterization of polyethersulfone/polyimide blend membranes prepared by a dry/wet phase inversion: Precipitation kinetics, morphology and gas separation," Journal of Membrane Science, vol. 351, no. 1-2, pp. 141-148, 2010.

[6] J. F. Bassetti, Preparação, Caracterização e Aplicação de Membranas Poliméricas Microporosas Assimétricas [Tese], Universidade Estadual de Campinas-UNICAMP, Campinas, Brazil, 2002.

[7] S. A. Altinkaya, H. Yenal, and B. Ozbas, "Membrane formation by dry-cast process: Model validation through morphological studies," Journal of Membrane Science, vol. 249, no. 1-2, pp. 163172, 2005.

[8] J. L. Thomas, M. Olzog, C. Drake, C. H. Shih, and C. C. Gryte, "Polyamide membrane precipitation studied by confocal backscattering microscopy," Polymer, vol. 43, no. 15, pp. 41534157, 2002.

[9] E. M. ARAÚJO, Tenacificação da Poliamida 6 com ABS por meio da Técnica de Compatibilização in situ com o uso de Copolímeros Acrílicos Reativos [Tese], Universidade Federal de São Carlos, São Carlos, Brazil, 2001.

[10] A. Ranade, N. A. D'Souza, B. Gnade, and A. Dharia, "Nylon-6 and montmorillonite-layered silicate (MLS) nanocomposites," Journal of Plastic Film and Sheeting, vol. 19, no. 4, pp. 271-285, 2003.

[11] H. J. Sue, K. T. Gam, N. Bestaoui, A. Clearfield, M. Miyamoto, and N. Miyatake, "Fracture behavior of $\alpha$-zirconium phosphatebased epoxy nanocomposites," Acta Materialia, vol. 52, no. 8, pp. 2239-2250, 2004.

[12] I. F. Leite, Preparação de nanocompósitos de poli(tereftalato de etileno)/bentonita [Dissertação], Universidade Federal de Campina Grande-UFCG, Campina Grande, Brazil, 2005.

[13] R. Pfaendner, "Nanocomposites: Industrial opportunity or challenge?" Polymer Degradation and Stability, vol. 95, no. 3, pp. 369-373, 2010

[14] A. M. D. Leite, Desenvolvimento de Membranas Assimétricas de Nanocompósitos de Poliamida 6/Argila por Inversão de Fases [Tese], Universidade Federal de Campina Grande-UFCG, Campina Grande, Brazil, 2011.

[15] P. S. SANTOS, Ciência E TEcnologia dE Argilas, vol. 1, Edgar Blucher, São Paulo, Brazil, 2nd edition, 1989.

[16] T. D. Fornes and D. R. Paul, "Crystallization behavior of nylon 6 nanocomposites," Polymer, vol. 44, no. 14, pp. 3945-3961, 2003.

[17] X. Hu and X. Zhao, "Effects of annealing (solid and melt) on the time evolution of polymorphic structure of PA6/silicate nanocomposites," Polymer, vol. 45, no. 11, pp. 3819-3825, 2004.

[18] Z. Zhao, W. Yu, Y. Liu, J. Zhang, and Z. Shao, "Isothermal crystallization behaviors of nylon- 6 and nylon- $6 /$ montmorillonite nanocomposite," Materials Letters, vol. 58, no. 5, pp. 802-806, 2004.

[19] Y. P. Khanna and W. P. Kuhn, "Measurement of crystalline index in nylons by DSC: complexities and recommendations," Journal of Polymer Science B: Polymer Physics, vol. 35, no. 14, pp. 22192231, 1997.

[20] S. S. Ray and M. Okamoto, "Polymer/layered silicate nanocomposites: a review from preparation to processing," Progress in Polymer Science, vol. 28, no. 11, pp. 1539-1641, 2003.

[21] T. D. Fornes, P. J. Yoon, H. Keskkula, and D. R. Paul, "Nylon 6 nanocomposites: the effect of matrix molecular weight," Polymer, vol. 42, no. 25, pp. 9929-9940, 2001. 

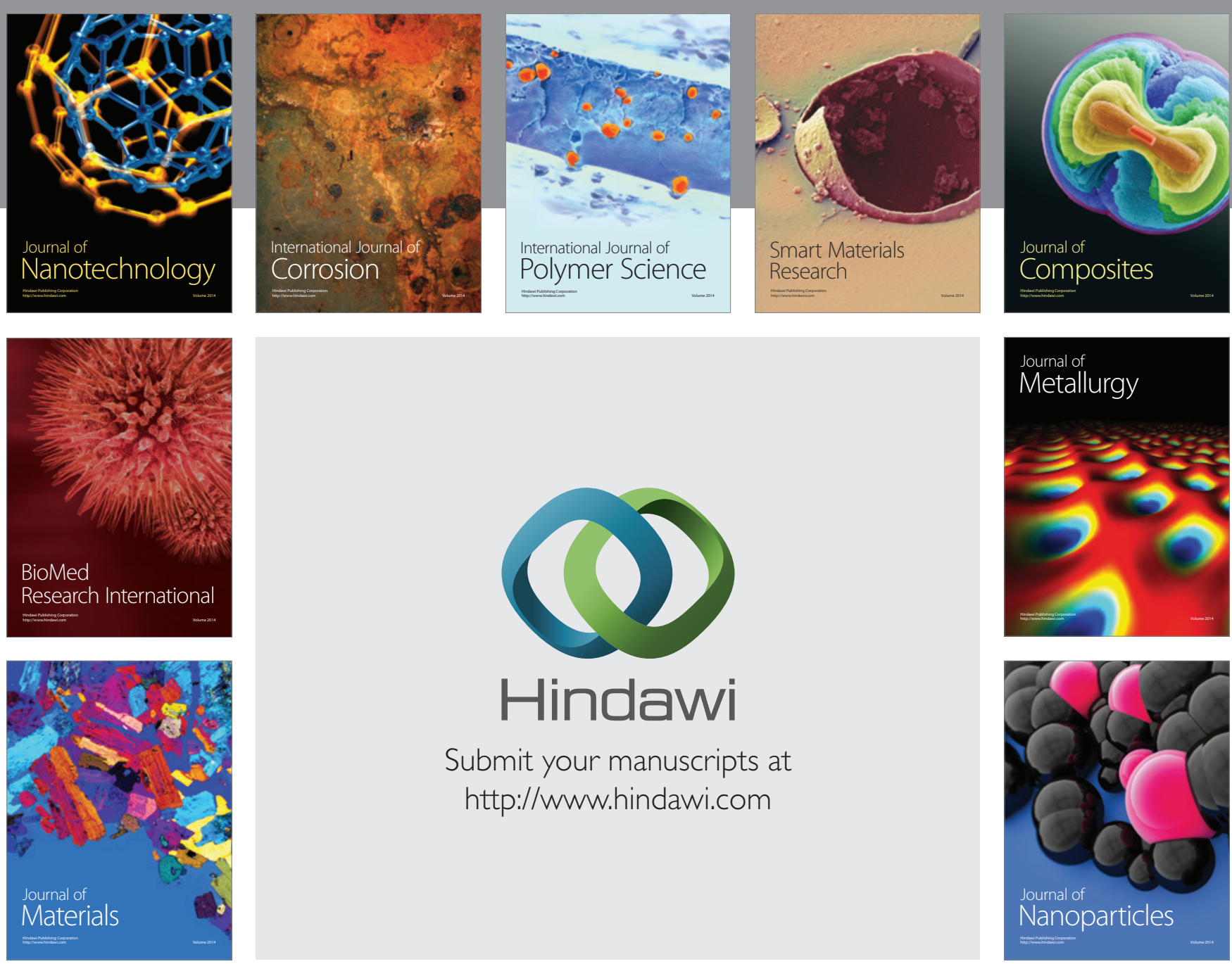

Submit your manuscripts at http://www.hindawi.com
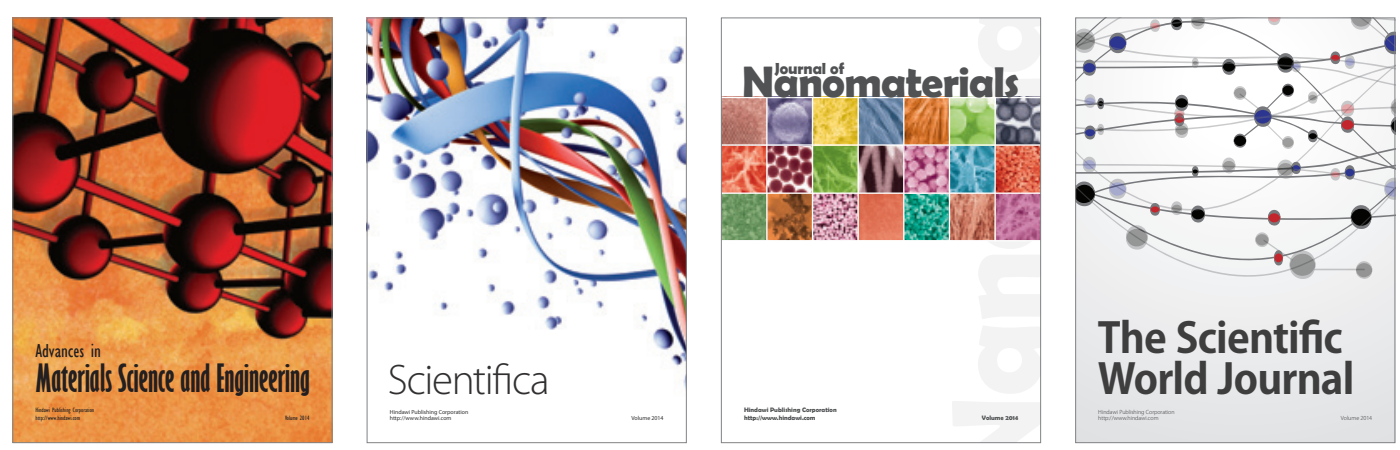

\section{The Scientific World Journal}
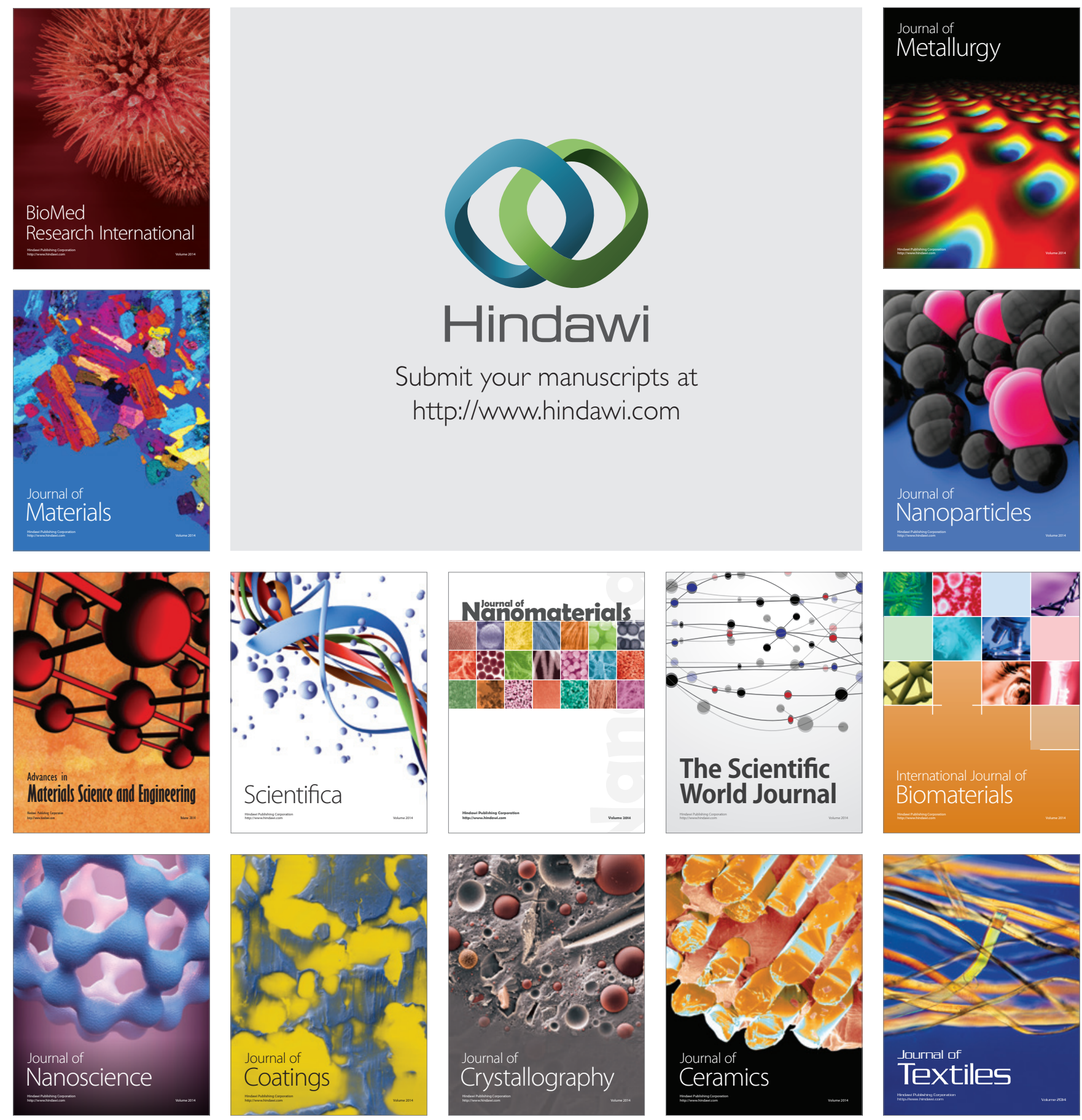